\title{
Size of snow particles in a powder-snow avalanche
}

\author{
Marie RASTELLO, ${ }^{1,2}$ Fabrice RASTELLO, ${ }^{3}$ Hervé BELLOT, ${ }^{2}$ Frédéric OUSSET, ${ }^{2}$ \\ François DUFOUR, ${ }^{4}$ Lorenz MEIER ${ }^{4}$ \\ ${ }^{1}$ Laboratoire de Mécanique des Fluides et d'Acoustique, Université de Lyon, École Centrale de Lyon, \\ CNRS-UCBL-INSA Lyon, 36 avenue Guy de Collongue, 69134 Ecully Cedex, France \\ E-mail: marie.rastello@ec-lyon.fr \\ ${ }^{2}$ Cemagref, Groupement de Grenoble, Unité de Recherche ETNA, 2 rue de la Papeterie, BP 76, \\ 38402 Saint-Martin-d'Hères Cedex, France \\ ${ }^{3}$ INRIA Laboratoire de I'Informatique du Parallélisme, Université de Lyon, ENS Lyon-CNRS-INRIA-UCBL, 46 allée d'Italie, \\ 69364 Lyon Cedex 07, France \\ ${ }^{4}$ WSL Institute for Snow and Avalanche Research SLF, Flüelastrasse 11, CH-7260 Davos Dorf, Switzerland
}

\begin{abstract}
Little quantitative information is available concerning the size of ice particles in the turbulent clouds of powder-snow avalanches. To quantify particle size distributions, we have developed an experimental device that collects particles in real-scale powder avalanches. The device was placed on the concrete bunker of the Swiss Vallée de la Sionne avalanche dynamics test site. On 31 January 2003, a large powder-snow avalanche struck the bunker and we were able to collect particle samples. The collected particles have been photographed and the pictures digitized. An image analysis tool allows us to determine an equivalent particle radius. The captured particles have a geometric mean of $0.16 \mathrm{~mm}$; the largest particles were $0.8 \mathrm{~mm}$ in size and the smallest particles $0.03 \mathrm{~mm}$.
\end{abstract}

\section{INTRODUCTION}

Powder-snow avalanches are a poorly understood physical phenomenon (Dufour and others, 2001). Although it is generally accepted that powder avalanches form as a result of a fast-flowing dense snow avalanche, the physical mechanisms involved in the formation and motion of the highly turbulent powder cloud are still the subject of much debate. The turbulent cloud flows above the dense flow, and an interaction between the two flows exists. Because the motion of the airborne cloud is less sensitive to terrain features, the cloud can decouple from the dense flow and often flows with enough force to cause considerable damage to forests and buildings. Instrumented field studies of powder-snow avalanches are difficult to realize, although macroscopic characteristics such as powder-cloud height and front velocity have been measured at the Swiss Vallée de la Sionne test site (Dufour and others, 2001; Biescas, 2003; Vallet and others, 2004) (Fig. 1). The measurements reveal that powder-snow avalanche heights can quickly reach $100 \mathrm{~m}$, while their velocity can exceed $100 \mathrm{~m} \mathrm{~s}^{-1}$.

Research efforts to understand powder-avalanche flow mechanics have concentrated on physical modelling coupled with laboratory experiments (Beghin and others, 1981; Hutter, 1996; Rastello and others, 2002; Ancey, 2004; Rastello and Hopfinger, 2004) and numerical modelling (Naaim, 1995; Sampl and Zwinger, 2004; Étienne and others, 2006; Turnbull and McElwaine, 2007). Comparisons have been made with gravity-driven suspensions (Simpson, 1997; Rastello and Hopfinger, 2004), gravity-driven plumes (Turnbull and others, 2007) and non-Boussinesq gravity clouds on steep slopes (Ancey, 2004; Rastello and Hopfinger, 2004).

All modelling approaches should reflect the fundamental characteristics of natural powder-snow avalanches. A poorly known quantity is the size of the snow particles in the powder-snow cloud. The behaviour of a turbulent dilute suspension (powder cloud) is highly dependent on the sedimentation velocity of the particles. The erosion or particle intake mechanism depends directly on the particle size (Rastello and Hopfinger, 2004). Furthermore, the selfmaintenance of the suspension strongly depends on the ratio between the sedimentation velocity of the particles and the avalanche velocity (Stacey and Bowen, 1988).

An error of a factor of 10 in the particle diameter leads to an error of a factor of 100 in the sedimentation velocity of the particles (Clift and others, 1978). In earlier work, Clément-Rastello (2001) reported a theoretical study that provides an order-of-magnitude estimate of the snow particles in a powder-snow avalanche. This work focused on the mechanisms present in a powder-snow avalanche and on how particle size is related to the evolution of the avalanche.

This paper tackles the problem from the experimental point of view: snow particles were captured inside a powder-snow avalanche, then stored and transferred to the laboratory where their size could be measured. The design and implementation of a device to capture particles from a powder-snow avalanche is described. The technique to process digital images of the captured particles to obtain particle size distributions is introduced, and the initial results are analysed and discussed.

\section{EXPERIMENTAL SET-UP}

The design of an experiment that captures snow particles in a powder-snow avalanche faces several difficulties as follows.

1. Velocities for a powder-snow avalanche are easily of the order of $60 \mathrm{~ms}^{-1}$ in the run-out zone and can reach $>100 \mathrm{~m} \mathrm{~s}^{-1}$ in the transit zone. The exposed area must be small and streamlined to reduce impact stresses. The device should be inexpensive because of the high probability of avalanche damage.

2. Health and safety dictates an upper limit of 5 min for standing in the avalanche path before it is artificially 


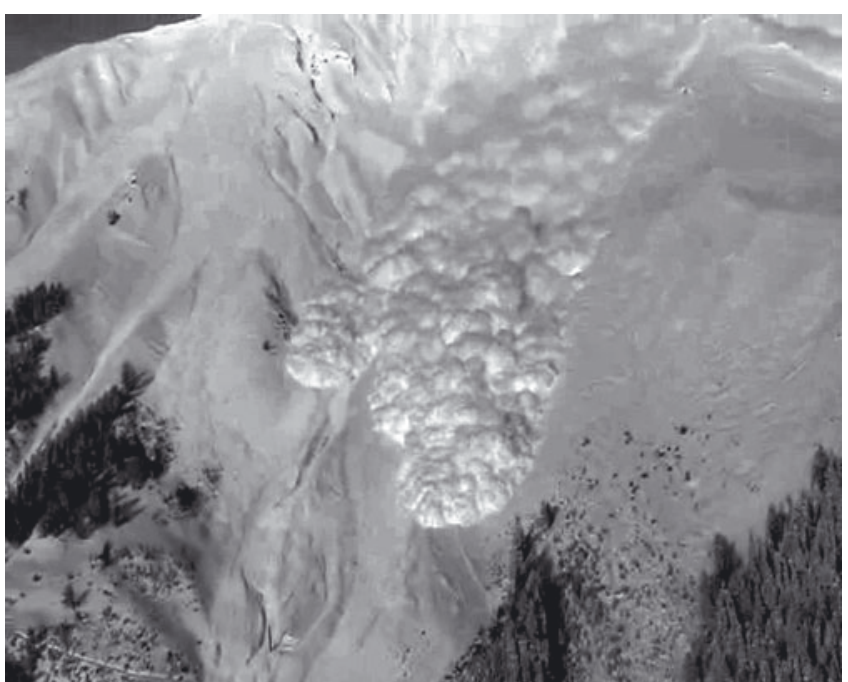

Fig. 1. Photograph of the avalanche triggered artificially at the Vallée de la Sionne avalanche test site in Switzerland on 31 January 2003 (courtesy of J. Le Goulm).

triggered. The device located in the running zone must be set within these time constraints.

3. After the avalanche, a time of $20 \mathrm{~min}$ to 1 hour is required to secure the avalanche path. During this time, the captured snow particles must not undergo any metamorphism.

4. Particular care is necessary to ensure that snow particles are not damaged while captured.

The snow-capturing device was designed and built with these limitations in mind (Figs 2 and 3).

Air and snow particles enter the device through a small tube $(\varnothing=0.02 \mathrm{~m})$ that widens to a cavity of diameter $0.4 \mathrm{~m}$.

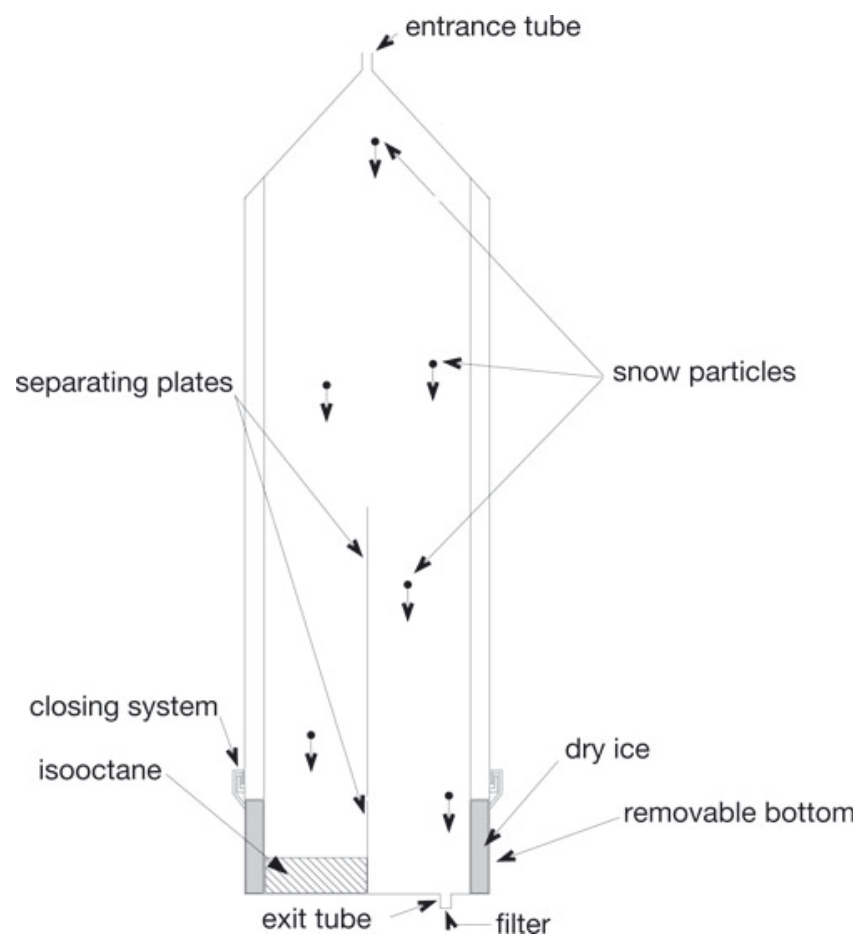

Fig. 2. Sketch of the device: section view.

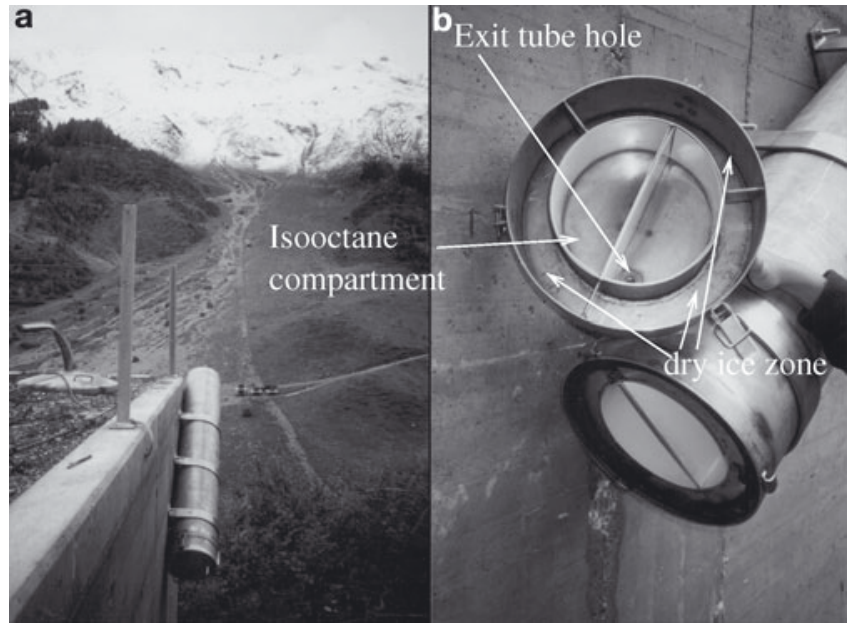

Fig. 3. (a) The experimental device fixed to the bunker of the Vallée de la Sionne test site and (b) the removable bottom.

This widening has the effect of slowing down the moving air by a factor of 400. An air velocity at the entrance of the tube of $60 \mathrm{~m} \mathrm{~s}^{-1}$ is thus reduced to $0.15 \mathrm{~m} \mathrm{~s}^{-1}$ within the instrument. Particle-drag forces then slow down the snow particles and prevent high-speed collisions of the particles with the collecting device. The tube is $1 \mathrm{~m}$ long.

Air is expelled through a $0.02 \mathrm{~m}$ diameter rear-facing tube. To prevent particles from filling the device, compacting and agglomerating, a ceramic filter has been included in the exit tube which allows air (but not snow) to exit the device. As soon as enough snow particles have filled the filter, no air or particle circulation is therefore possible in the device.

Snow particles can be conserved without any metamorphism occurring for many months if they are immersed in isooctane at temperatures lower than $0^{\circ} \mathrm{C}$ (Brun and Pahaut, 1991). The bottom of the device was therefore equipped with a removable section (Fig. 3b). This section has three compartments, two in the centre and one on the outside. The first contains the exit tube and the filter. The second, into which isooctane is poured, collects the snow particles. The third, located on the outside, contains dry ice. The dry ice cools the isooctane to a temperature below $0^{\circ} \mathrm{C}$, preventing snow particles from undergoing any metamorphism before they can be collected.

The device is made of stainless steel, and the inner part is partially covered in Teflon to prevent snow particles from sticking to the cold metal. Since it is mounted at a $45^{\circ}$ angle to the horizontal plane in the axis of the avalanche path (Fig. 3a), gravity helps both the deposition process and the isooctane to remain in its compartment.

\section{EXPERIMENTAL PROCEDURE Collection of particles}

The device was fixed on the side of the bunker at the Vallée de la Sionne test site. A large, mixed snow avalanche (No. 506) depicted in Figure 1 was artificially triggered on 31 January 2003 (Biescas, 2003; Sovilla and others, 2006).

This avalanche has been discussed in detail by Christen and others (2010). It was released at $0934 \mathrm{~h}$ from the Crêta Besse 2 release zone. The release area was $\sim 92000 \mathrm{~m}^{2}$, with a volume of $77550 \mathrm{~m}^{3}$ (assuming a mean fracture height of 


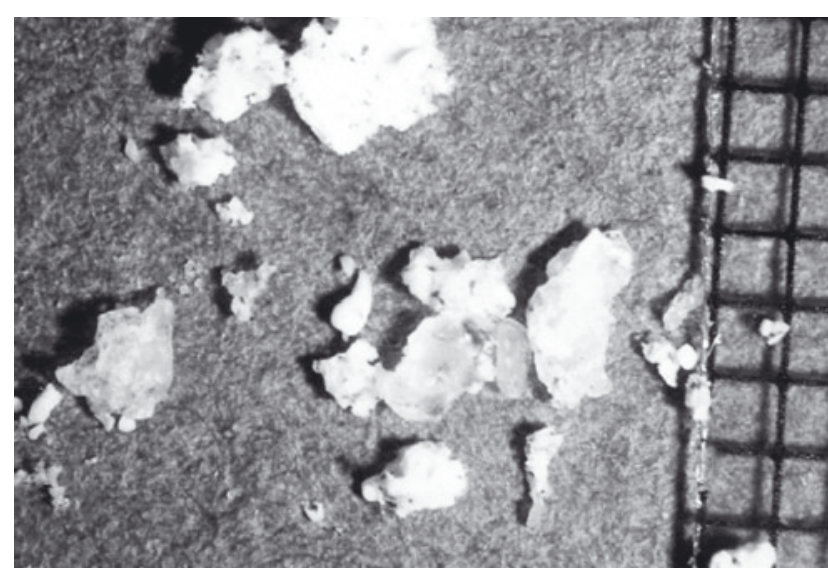

Fig. 4. Initial picture.

$\sim 0.84 \mathrm{~m}$ and width of $450 \mathrm{~m}$ over $200 \mathrm{~m}$ ). The difference in altitude covered by the avalanche was $1200 \mathrm{~m}$. Its width was of the order of $300-450 \mathrm{~m}$. Front velocities of the order of $50-60 \mathrm{~m} \mathrm{~s}^{-1}$ were measured by video analysis.

Snow particles from the powder-snow part of the avalanche were collected. The dense flowing component stopped before reaching the bunker, which is located $100 \mathrm{~m}$ higher on the counterslope of the avalanche path. The avalanche deposits at the valley bottom reached $6.5 \mathrm{~m}$. Twenty minutes after the avalanche event, the rear face of the device was opened to transfer the collected particles into small boxes filled with isooctane and cooled with dry ice. The device contained $\sim 650$ particles which were perfectly separated from each other with no trace of compaction or damage. The boxes were subsequently preserved below $0^{\circ} \mathrm{C}$ before the imaging processing was performed.

\section{Images of the snow particles}

The snow particles were transported to the Laboratoire de Glaciologie et Géophysique de l'Environnement, Grenoble, France (LGGE), where the image processing was realized in a cold chamber. Air temperature in the chamber was maintained between -20 and $-30^{\circ} \mathrm{C}$, and no metamorphism of the snow was observed throughout the process. Snow particles were transferred from the boxes onto pieces of coloured paper. Pictures were taken only after the thin isooctane film, initially present, had completely volatilized. A digital camera, equipped with a zoom and fixed on a rack, was used. A ruler was included in each picture of the particles so that pixel dimensions could be accurately scaled.

\section{IMAGE AND DATA PROCESSING}

The goal is to measure an equivalent radius of particles from the digital pictures. Because pictures are inherently only two-dimensional (2-D), the third dimension of the particle is not accessible to us. Another difficulty arose from isooctane capillarity that makes it difficult to find small particles. It is difficult to distinguish between naturally agglomerated particles and those joined by residual isooctane. The task was complicated by the fact that the typical minimal precision (one pixel) of a picture corresponds to $0.02 \mathrm{~mm}$, while the equivalent radius of many particles is $\sim 0.1 \mathrm{~mm}$.

The image processing was divided into the following steps.

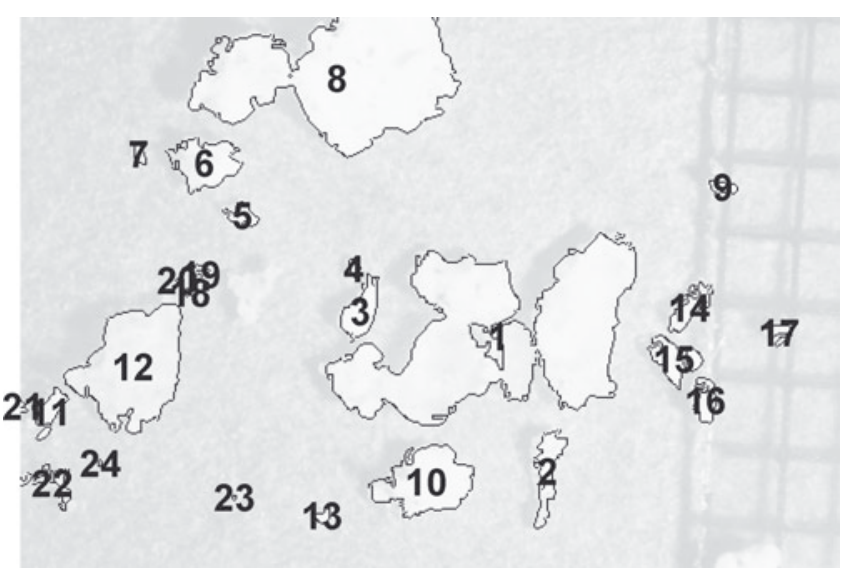

Fig. 5. Particle regions (24 were found) corresponding to Figure 4.

\section{Dynamic thresholding}

Pixels of the image classified as part of a particle are separated from the background of the picture using dynamic thresholding (Gonzalez and Woods, 1992). The particle region grows iteratively starting from an initial point selected manually; each adjacent point of a similar colour is also classified as the particle region. The notion of similarity of colours is a simple threshold (Gonzalez and Woods, 1992) on the Euclidean distance between colour vectors.

The designed image-processing tool allows each particle region to be tuned to the value of the threshold by a visual check of the result. The corresponding particle regions of the image of Figure 4 are depicted in Figure 5.

\section{Aggregation}

A particle (represented by an ellipsoid shape in Fig. 6) will be considered as an aggregate of subparticles. Particle regions are manually divided into subparticles, as depicted in Figure 7.

This process of aggregation allows us to distinguish three cases:

1. a lower bound for particle size is obtained by considering that each particle is composed of only one subparticle;

2. an upper bound for particle size is obtained by considering that each particle is composed of all adjacent subparticles, i.e. all subparticles of a particle region;

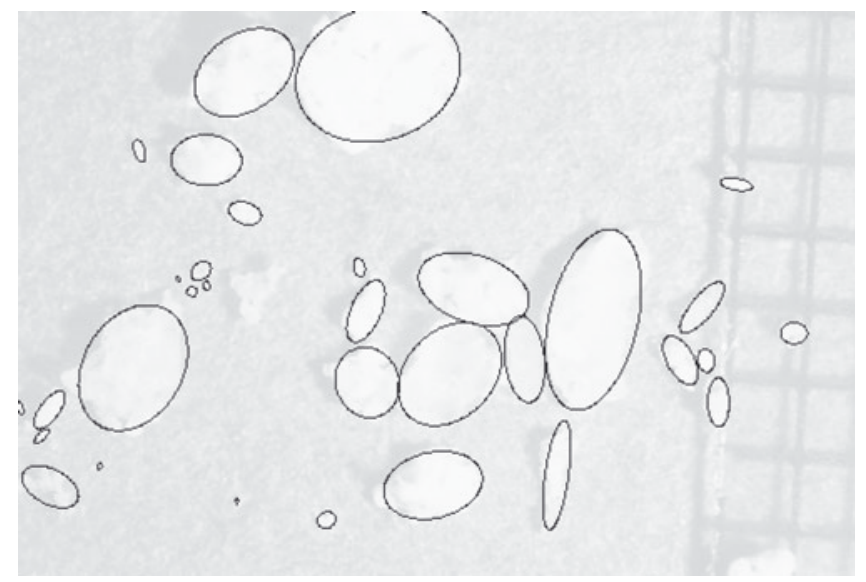

Fig. 6. Particles and their corresponding ellipses. 


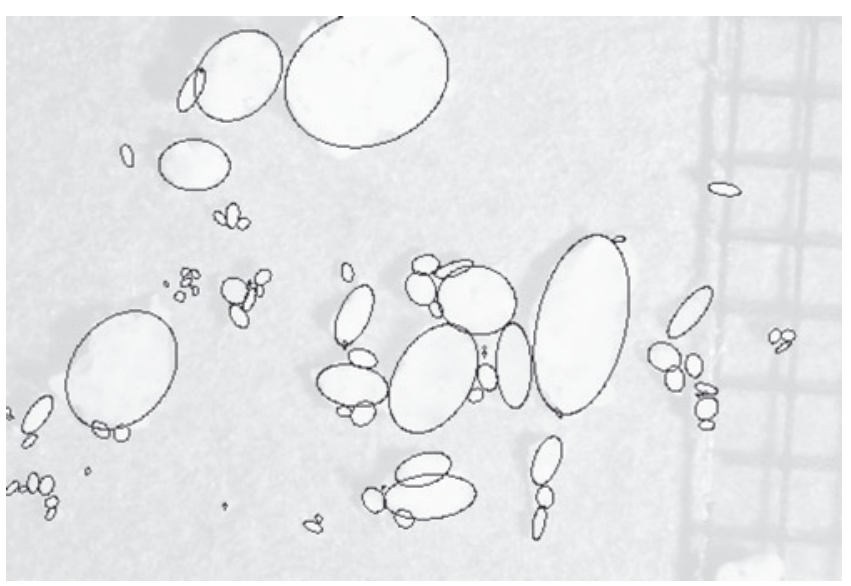

Fig. 7. Manually delimited subparticles and their corresponding ellipses.

3. an intermediate value (more realistic) for particle size is obtained by choosing the aggregates manually.

\section{Particle volume}

The 2-D image of each subparticle is first represented by an ellipse that has the same normalized second central moments (Teague, 1980) (Fig. 7). Let $A$ and a be the major and minor axes, respectively, of this 2-D ellipsoid. The subparticle is then represented by a three-dimensional (3-D) ellipsoid of axis lengths $(A, a, a)$. The volume of each subparticle is evaluated as the volume of this 3-D ellipsoid. The volume of a particle is the sum of the volume of its composite subparticles. We define the size of the particle to be the equivalent radius, i.e. the radius of the sphere that has the same volume as the particle.

This procedure is not the only way to evaluate the size of the particles; other characteristic sizes exist. Colbeck and others (1990) defined the size of a particle as the greatest extension. They noticed that it could be defined differently and mention two other different methods for measuring the size of particles: stereology and sieving. The authors outline the fact that the different methods provide different results.

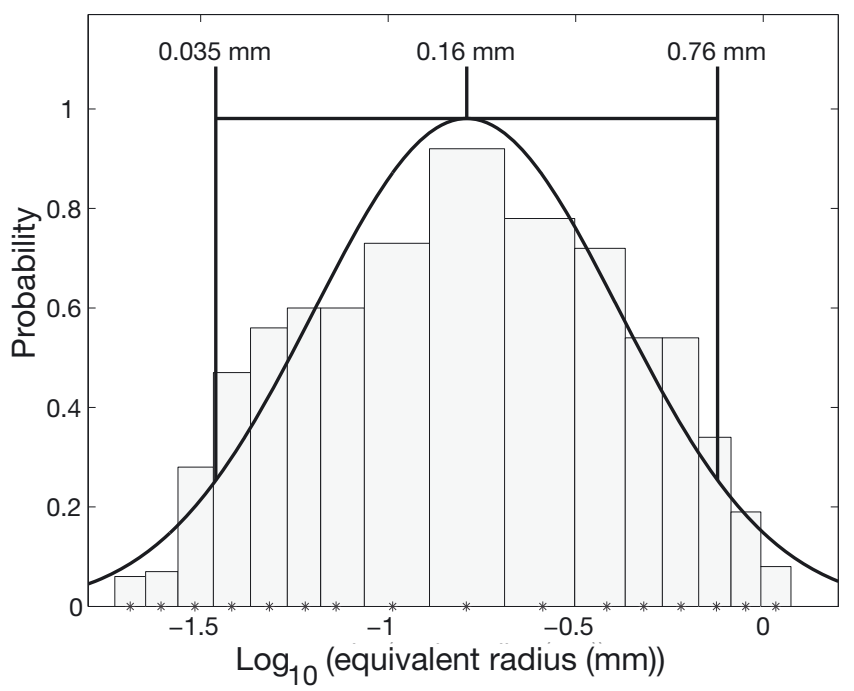

Fig. 8. Logarithm of the particle size fitted with a normal distribution.

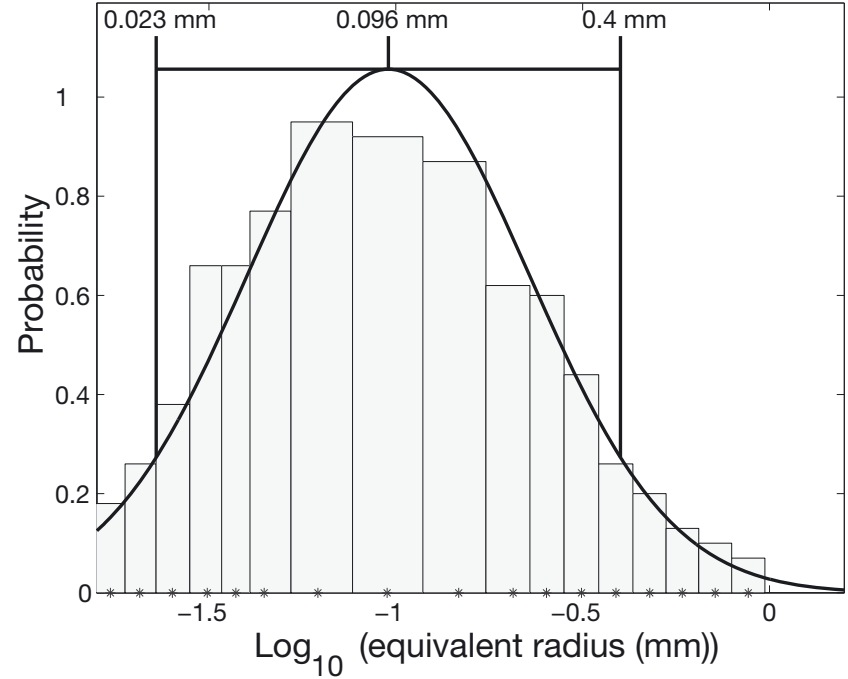

Fig. 9. Logarithm of subparticle size fitted with a normal distribution.

Gay and others (2002) have proposed a method to measure the size of particles using image processing. A Sobel operator (gradient) (Gonzalez and Woods, 1992) is used to separate particles from the background. For each particle, a so-called 'skeleton' is built. The method yields the mean convex radius, which is the average of the radii associated with each endpoint of the skeleton. The problem with this method is that end-points depend upon the resolution of the image. Most sizes obtained are between 0.1 and $0.3 \mathrm{~mm}$.

\section{RESULTS AND DISCUSSION}

The above image-processing technique applied to the set of images gives us the equivalent radius distribution for the subparticles, the intermediate case and the upper bound. The upper bound represents the maximum value for the equivalent radius of the snow particles present in the sample.

As can be seen in Figure 5, the automatic aggregation of the adjacent subparticles can sometimes give unrealistic particles (e.g. particle 1 in Fig. 5). The distribution of subparticles represents particles before clustering. Clustering should have occurred before or during the avalanche, but not during the gathering.

This provides a pessimistic lower bound for the particle equivalent radius. The obtained distribution for the intermediate equivalent radius of particles (corresponding radius given in millimetres) can be fitted by a log-normal distribution.

Figure 8 depicts a histogram of the logarithm (base 10) of the equivalent radius fitted by a normal distribution. The arithmetic mean and standard deviation $(\mu, \sigma)$ for the logarithm of the measured equivalent radii are $(-0.79,0.41)$. This gives a geometric mean and standard deviation $\left(\mu_{\mathrm{G}}, \sigma_{\mathrm{G}}\right)$ for the set of measured equivalent radii of $(0.16,2.57)$. Therefore, $90 \%$ of particles have an equivalent radius between 0.03 and $0.8 \mathrm{~mm}$, with a (geometric) mean radius of $0.2 \mathrm{~mm}$.

The upper bound has similar values, with particle radii between 0.03 and $0.9 \mathrm{~mm}$ and a (geometric) mean radius of $0.2 \mathrm{~mm}$. The obtained distribution for subparticles is also well fitted by a log-normal distribution with $(\mu, \sigma)=$ $(-1.02,0.38)$ (Fig. 9). This gives a pessimistic lower bound of 
particle radius between 0.02 and $0.4 \mathrm{~mm}$, with a (geometric) mean radius of $0.1 \mathrm{~mm}$.

Clément-Rastello (2001) performed a theoretical study of the size of the particles present in a powder-snow avalanche. The study considered typical particle sizes present in the snow layer and then modelled different processes present in a powder-snow avalanche that impact the selection of the particles. The estimate obtained for the upper limit of the particle radius was $0.1 \mathrm{~mm}$. The agreement with the present results is therefore encouraging.

Log-normal distributions have frequently been found for raindrops (Feingold and Levin, 1986) and snow particles (Nolin and others, 1992). Rounded/wet snow particles (Colbeck, 1986, 1987; Espin, 2003) follow a log-normal distribution, while airborne grains have been fitted by Clifton and others (2006) using a two-parameter gamma distribution. Bartelt and McArdell (2009) found log-normal distributions for the size of the granules in the deposit of different dry and wet dense avalanches.

We are not aware of any results concerning size distribution of precipitation snow particles; nevertheless, they may reasonably behave as raindrops. Note that the size of the particles probably changes during the avalanche. Local shear due to turbulence, collisions and energy dissipation may lead to fragmentation, melting or fusion. Log-normal distributions are classically used when dealing with splitting (Shinnar, 1961; Cheng and Redner, 1988), coalescing or crushing (A. Fujihara and others, http://iopscience.iop.org/17426596/31/1/038).

The size of particles in the snow cover has been widely measured in different contexts (e.g. Mellor, 1964; Shi and Dozier, 2000; Gay and others, 2002; Dozier and Painter, 2004). Most measured mean equivalent radii are between 0.1 and $0.8 \mathrm{~mm}$ (Fig. 10). The largest snow particles can reach several millimetres.

\section{CONCLUSION}

We have designed a device to capture snow particles in a powder-snow avalanche. Compaction and agglomeration of particles have been avoided due to a ceramic filter positioned at the exit of the tube. The device slows down the particles to avoid particle commutations by collisions. Particles have been protected from any metamorphism by preserving them with isooctane and dry ice. Snow particles were collected in the powder-snow part of a mixed avalanche triggered on the Vallée de la Sionne experimental test site.

Images of the snow particles were taken in a cold chamber, and studied using an image-processing technique developed for this purpose. Each particle is decomposed into subparticles, and its volume is the sum of these. A subparticle has been represented as a 3-D ellipsoid $(A, a, a)$ where $A$ is the major axis and $a$ the minor axis of an ellipse with the same normalized second central moment as the 2-D image of the subparticle. Image processing was also used to separate adjacent particles.

The obtained distribution of particle equivalent radii $(\mathrm{mm})$ has been fitted by a log-normal distribution. The geometric mean and the geometric standard deviation $\left(\mu_{\mathrm{G}}, \sigma_{\mathrm{G}}\right)$ of the set of measured equivalent radii were $(0.16,2.57)$, giving a particle equivalent radius of $0.03-0.8 \mathrm{~mm}$, with a (geometric) mean equivalent radius of $0.2 \mathrm{~mm}$.

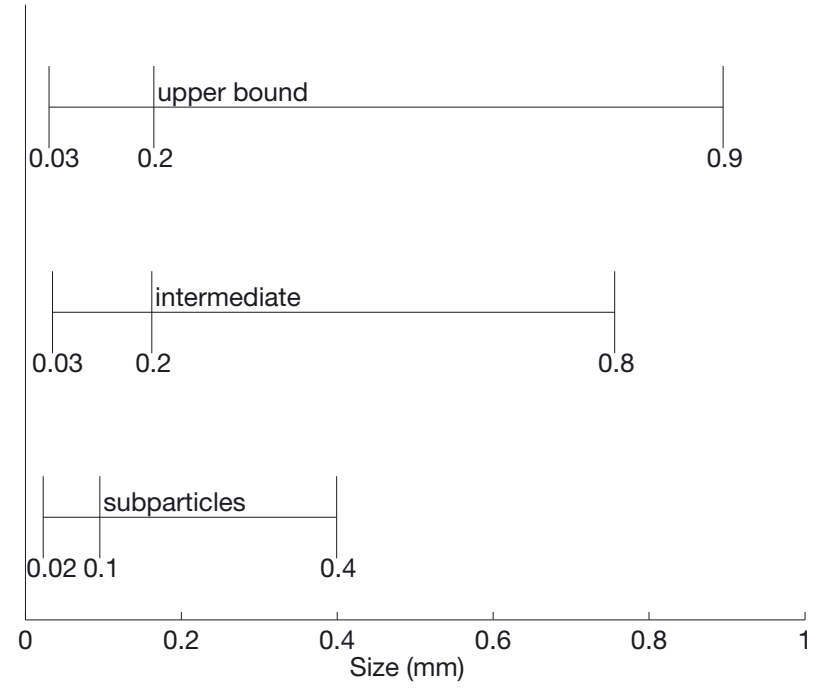

Fig. 10. Equivalent radius of particles.

\section{ACKNOWLEDGEMENTS}

We thank the SLF for access to the Vallée de la Sionne test site. We also thank J. Meyssonnier for helping to take the pictures. The experimental set-up was realized during M. Rastello's PhD research, under the supervision of C. Ancey and E.J. Hopfinger.

\section{REFERENCES}

Ancey, C. 2004. Powder snow avalanches: approximation as non-Boussinesq clouds with a Richardson number-dependent entrainment function. J. Geophys. Res., 109(F1), F01005. (10.1029/2003JF000052.)

Bartelt, P. and B.W. McArdell. 2009. Granulometric investigations of snow avalanches. J. Glaciol., 55(193), 829-833.

Beghin, P., E.J. Hopfinger and R.E. Britter. 1981. Gravitational convection from instantaneous sources on inclined boundaries. J. Fluid Mech., 107, 407-422.

Biescas, G.B. 2003. Aplicación de la sismología al estudio y detección de aludes de nieve. (PhD thesis, Universitat de Barcelona.)

Brun, E. and E. Pahaut. 1991. An efficient method for a delayed and accurate characterization of snow grains from natural snowpacks. J. Glaciol., 37(127), 420-422.

Cheng, Z. and S. Redner. 1988. Scaling theory of fragmentation. Phys. Rev. Lett., 60(24), 2450-2453.

Christen, M., J. Kowalski and P. Bartelt. 2010. RAMMS: numerical simulation of dense snow avalanches in three-dimensional terrain. Cold Reg. Sci. Technol., 63(1-2), 1-14.

Clément-Rastello, M. 2001. A study on the size of snow particles in powder-snow avalanches. Ann. Glaciol., 32, 259-262.

Clift, R., J.R. Grace and M.E. Weber. 1978. Bubbles, drops and particles. London, Academic Press.

Clifton, A., J.D. Rüedi and M. Lehning. 2006. Snow saltation threshold measurements in a drifting-snow wind tunnel. J. Glaciol., 52(179), 585-596.

Colbeck, S.C. 1986. Statistics of coarsening in water-saturated snow. Acta Metall., 34(3), 347-352.

Colbeck, S.C. 1987. A review of the metamorphism and classification of seasonal snow cover crystals. IAHS Publ. 162 (Symposium at Davos 1986 - Avalanche Formation, Movement and Effects), $3-34$. 
Colbeck, S.C. and 7 others. 1990. The international classification for seasonal snow on the ground. Wallingford, Oxon, International Association of Scientific Hydrology.

Dozier, J. and T.H. Painter. 2004. Multispectral and hyperspectral remote sensing of alpine snow properties. Annu. Rev. Earth Planet. Sci., 32, 465-494.

Dufour, F., U. Gruber and W. Ammann. 2001. Avalanches: études effectuées dans la Vallée de la Sionne en 1999. Les Alpes, 2, $9-15$.

Espin, D. 2003. Experimental and computational investigation of snow melting on a hydronically heated concrete slab. (MS thesis, University of Oklahoma.)

Étienne, J., M. Rastello and E.J. Hopfinger. 2006. Modelling and simulation of powder-snow avalanches. C. R. Mécanique, 334(8-9), 545-554.

Feingold, G. and Z. Levin. 1986. The lognormal fit to raindrop spectra from frontal convective clouds in Israel. J. Climate Appl. Meteorol., 25(10), 1346-1363.

Gay, M., M. Fily, C. Genthon, M. Frezzotti, H. Oerter and J.G. Winther. 2002. Snow grain-size measurements in Antarctica. J. Glaciol., 48(163), 527-535.

Gonzalez, R.C. and R.E. Woods. 1992. Digital image processing. London, Addison-Wesley.

Hutter, K. 1996. Avalanche dynamics. In Singh, V.P., ed. Hydrology of disasters. Dordrecht, etc., Kluwer Academic Publishers, 317 394.

Mellor, M. 1964. Properties of snow. CRREL Monogr. III-A1.

Naaim, M. 1995. Modélisation numérique des avalanches aérosols. Houille Blanche, 50(5-6), 56-62.

Nolin, A.W., J. Shi and J. Dozier. 1992. Characterization of snow grain size in the near-infrared and microwave wavelengths. In Proceedings of IEEE Topical Symposium on Combined Optical, Microwave, Earth and Atmosphere Sensing, 22-25 March, 1993, Albuquerque, NM, USA. Piscataway, NJ, Institute of Electrical and Electronics Engineers, 51-54.
Rastello, M.C. and E.J. Hopfinger. 2004. Sediment-entraining suspension clouds: a model of powder-snow avalanches. J. Fluid Mech., 509, 181-206.

Rastello, M., C. Ancey, F. Ousset, R. Magnard and E.J. Hopfinger. 2002. An experimental study of particle-driven gravity currents on steep slopes with entrainment of particles. Natur. Hazards Earth Syst. Sci. (NHESS), 2(3-4), 181-185.

Sampl, P. and T. Zwinger. 2004. Avalanche simulation with SAMOS Ann. Glaciol., 38, 393-398.

Shi, J. and J. Dozier. 2000. Estimation of snow water equivalence using SIR-C/X. Part I: inferring snow density and subsurface properties. IEEE Trans. Geosci. Remote Sens., 38(6), 2465-2474.

Shinnar, R. 1961. On the behaviour of liquid dispersions in mixing vessels. J. Fluid Mech., 10(2), 259-275.

Simpson, J.E. 1997. Gravity currents in the environment and in the laboratory. Second edition. Cambridge, etc., Cambridge University Press.

Sovilla, B., P. Burlando and P. Bartelt. 2006. Field experiments and numerical modelling of mass entrainment in snow avalanches. J. Geophys. Res., 111(F3), F03007. (10.1029/2005JF000391.)

Stacey, M. and A. Bowen. 1988. The vertical structure of turbidity currents and a necessary condition for self-maintenance. J. Geophys. Res., 93(C4), 3543-3553.

Teague, M.R. 1980. Image analysis via the general theory of moments. J. Opt. Soc. Am., 70(8), 920-930.

Turnbull, B. and J.N. McElwaine. 2007. A comparison of powdersnow avalanches at Vallée de la Sionne, Switzerland, with plume theories. J. Glaciol., 53(180), 30-40.

Turnbull, B., J.N. McElwaine and C. Ancey. 2007. The KulikovskiySveshnikova-Beghin model of powder snow avalanches: development and application. J. Geophys. Res., 112(F1), F01004. (10.1029/2006JF000489.)

Vallet, J., B. Turnbull, S. Joly and F. Dufour. 2004. Observations on powder snow avalanches using videogrammetry. Cold Reg. Sci. Technol., 39(2-3), 153-159. 